\title{
Use of the Quantitatively Transformed Field Soil Structure Description of the US National Pedon Characterization Database to Improve Soil Pedotransfer Function
}

\author{
Sung Won Yoon, Daniel Gimenez ${ }^{1}$, Attila Nemes ${ }^{2}$, Hyen Chung Chun, Yong Seon Zhang, \\ Yeon Kyu Sonn, Seong Soo Kang, Myung Sook Kim, Yoo Hak Kim*, and Sang Keun Ha* \\ National Academy of Agricultural Science, Rural Development Administration, Suin ro, $150^{\text {th }}$ (250 $0^{\text {th }}$, Seodun-dong) \\ Gwonseon-gu, Suwon, Gyeonggi-do, Republic of Korea (441-707), 'Department of Environmental Sciences, Rutgers, \\ The State University of New Jersey, 14 College Farm Rd. New Brunswick, NJ 08901 USA, \\ ${ }^{2}$ Univ. of Maryland, Dep. of Plant Science and Landscape Architecture \\ 2102 Plant Science Building College Park, MD 20742 USA
}

Soil hydraulic properties such as hydraulic conductivity or water retention which are costly to measure can be indirectly generated by soil pedotransfer function (PTF) using easily obtainable soil data. The field soil structure description which is routinely recorded could also be used in PTF as an input to reduce the uncertainty. The purposes of this study were to use qualitative morphological soil structure descriptions and soil structural index into PTF and to evaluate their contribution in the prediction of soil hydraulic properties. We transformed categorical morphological descriptions of soil structure into quantitative values using categorical principal component analysis (CATPCA). This approach was tested with a large data set from the US National Pedon Characterization database with the aid of a categorical regression tree analysis. Six different PTFs were used to predict the saturated hydraulic conductivity and those results were averaged to quantify the uncertainty. Quantified morphological description was successively used in multiple linear regression approach to predict the averaged ensemble saturated conductivity. The selected stepwise regression model with only the transformed morphological variables and structural index as predictors predicted the $K_{\text {sat }}$ with $\mathbf{r}^{2}=0.48(p=0.018)$, indicating the feasibility of CATPCA approach. In a regression tree analysis, soil structure index and soil texture turned out to be important factors in the prediction of the hydraulic properties. Among structural descriptions size class turned out to be an important grouping parameter in the regression tree. Bulk density, clay content, W33 and structural index explained clusters selected by a two step clustering technique, implying the morphologically described soil structural features are closely related to soil physical as well as hydraulic properties. Although this study provided relatively new method which related soil structure description to soil structure index, the same approach should be tested using a datasets containing the actual measurement of hydraulic properties. More insight on the predictive power of soil structure index to estimate hydraulic properties would be achieved by considering measured the saturated hydraulic conductivity and the soil water retention.

Key words: Soil structure, Water retention characteristics, Pedo-transfer function, Categorical principle component analysis, Hydraulic conductivity

\section{Introduction}

The performance of hydrological models relies, among others, on the selection of hydraulic input parameters such as

Received : July 20. 2011 Accepted : October 13. 2011

*Corresponding author : Phone: +82312900328, 312900311

E-mail: kim.yoohak@korea.kr, ha0sk@korea.kr soil water retention and hydraulic conductivity. It is difficult to measure these properties because their measurements are time consuming and costly, especially for the characterization of large areas of land (Nemes et al., 2006; Pachepsky and Rawls, 2003). An alternative is to predict these properties from more readily available soil data (e.g., particle sizes, bulk density and/or organic matter content) using pedotransfer functions, PTFs (Nemes et al., 2006; Pachepsky et al., 
2006; Rawls et al., 1998), which are defined as relationships between soil properties or characteristics (Wosten et al., 1990).

Soil structure is characterized in the field by describing visible units of soil peds or inferred by soil physical properties such as bulk density or water retention (Rawls and Pachepsky, 2002). Shape, size, and grade (i.e., relative distinctness of soil structural units) of soil clods are considered to regulate many of the hydrological processes related to soil water, solute transport, and runoff from tilled landscapes (Holden, 1995; Levine et al., 1996; Lin et al., 1999; McKenzie et al., 1991; Pachepsky and Rawls, 2003). Previous studies confirmed that there is potential in using qualitative descriptions to assess the change of soil structure along a chronosequence (Calero et al., 2008; Schaetzl and Anderson, 2005), and for estimation of water retention and hydraulic properties (Levine et al., 1996; Lilly et al., 2008; Lin et al., 1999; Pachepsky and Rawls, 2003). Due to the non-numerical characteristics of soil structural descriptions, however, it is difficult to evaluate relationships among soil structural descriptions and other soil properties or hydraulic processes using most traditional PT methods (Pachepsky and Rawls, 2003). A few studies identified relationships between soil structure and physical properties from soil databases using artificial neural networks (Levine et al., 1996) or regression trees techniques (Guber et al., 2003; Lilly et al., 2008; Pachepsky and Rawls, 2003; Pachepsky et al., 2006). Pachepsky and Rawls (2003) utilized a regression tree technique to estimate water retention at $-33 \mathrm{kPa}$ and $-1500 \mathrm{kPa}$ from the US National Pedon Characterization database. Lilly et al.
(2008) investigated the significance of soil horizons, structure unit sizes, and soil textures in the estimation of saturated hydraulic conductivity by assigning dummy variables to qualitative soil structure descriptions.

The objectives of this study were to investigate how qualitative soil morphological features such as aggregate size, shape and grade, dry/moist consistence, stickiness and plasticity from the US National Pedon Characterization database are related to soil physical and hydraulic properties such as clay content, bulk density, organic matter, water content at $-33 \mathrm{kPa}(\mathrm{W} 33)$ and at $-1500 \mathrm{kPa}(\mathrm{W} 1500)$, and saturated hydraulic conductivity. The relative significance of soil properties in the estimation of W33 and bulk density was investigated with transformed morphological variables using regression tree analyses.

\section{Materials and Methods}

Data selection from the US National Pedon Characterization database $A$ total of 1468 soil horizons were selected from the US National Pedon Characterization database (Table 1). Each sample contained field morphological descriptions of aggregates shapes (granular, wedge, blocky, platy, and prismatic), sizes (fine, medium, and coarse) and grades (weak, moderate, and strong), dry (soft and hard) and moist (loose and friable) consistency, plasticity (non, slightly, moderately, and very), stickiness (non, slightly, moderately, and very), field textural class, bulk density $(\mathrm{BD})$, organic matter $(\mathrm{OM})$, particle size distribution (at least five data points) and volumetric water

Table 1. Number of samples as functions of shape and texture classes. Numbers in parenthesis are samples used in the multi model ensemble prediction.

\begin{tabular}{|c|c|c|c|c|c|}
\hline \multirow{2}{*}{ Texture } & \multicolumn{5}{|c|}{ Shape } \\
\hline & Crumble \& Granular & Platy & Blocky & Prismatic & Total \\
\hline$S$ & 11 & 7 & 45 & 4 & 67 \\
\hline LS & 10 & 4 & 48 & 2 & 64 \\
\hline SL & $49(48)$ & 18 & $221(216)$ & $27(25)$ & $315(307)$ \\
\hline $\mathrm{L}$ & 34 & $22(20)$ & $149(145)$ & $19(17)$ & $224(216)$ \\
\hline $\mathrm{SiL}$ & 51 & $72(69)$ & $293(279)$ & $82(74)$ & $498(473)$ \\
\hline $\mathrm{Si}$ & 0 & 1 & 3 & 2 & 6 \\
\hline SCL & 7 & 2 & $47(45)$ & 7 & $63(61)$ \\
\hline CL & 2 & 1 & $20(18)$ & $6(5)$ & $29(26)$ \\
\hline $\mathrm{SiCL}$ & $22(19)$ & $11(10)$ & 94 (74) & $27(20)$ & $154(123)$ \\
\hline $\mathrm{SiC}$ & $2(1)$ & 4 & $30(8)$ & $1(0)$ & 37 (13) \\
\hline $\mathrm{C}$ & 1 & 1 & $5(0)$ & $4(1)$ & $11(3)$ \\
\hline Total & 189 (184) & $143(137)$ & $955(881)$ & $181(157)$ & 1468 (1359) \\
\hline
\end{tabular}


contents at pressure potentials of $-33 \mathrm{kPa}$ (W33) and of $-1500 \mathrm{kPa}$ (W1500). Over $64 \%$ of soils were classified as blocky shape and around $76 \%$ of soils were in the texture classes sandy loam, loam, and silt loam (Table 1). It should also be noted that there were only few samples available in clay $(\mathrm{C})$, silty clay ( $\mathrm{SiC})$, clay loam $(\mathrm{CL})$ and silt (Si).

In this study, data having soil particle size distributions with a minimum of five data points were fitted with the lognormal density function defined as:

$$
F(\ln d)=\frac{1}{2}\left[1+\operatorname{erf}\left(\frac{\ln d-\ln d_{m}}{\sigma_{d} \sqrt{2}}\right)\right]
$$

where $\ln \mathrm{d}$ is the log-converted particle diameter, $\ln \mathrm{d}_{\mathrm{m}}$ is the mean and $\sigma_{\mathrm{d}}$ is the standard deviation of $\ln \mathrm{d}$. In the dataset, the size of each structural shape considered was classified into three size classes: fine, medium, coarse. The original size classification was converted to actual size using the classification of Nikiforoff (1941) shown in Table 2.

The Soil Water Retention Model and Soil Structural Index The lognormal water retention model of Kosugi (1996) was fitted to all water retention data. The Kosugi (1996) water retention model assumes a lognormal distribution of pore radii, $r$, of the form:

$$
f(r)=\frac{\theta_{s}-\theta_{r}}{r \sigma \sqrt{2 \pi}} \exp \left(-\frac{\left[\ln \left(r / r_{s}\right)\right]^{2}}{2 \sigma_{s}^{2}}\right)
$$

where $\theta_{\mathrm{s}}$ and $\theta_{\mathrm{r}}$ are the saturated and residual water contents, respectively, $r_{\mathrm{s}}$ is the median pore radius and $\sigma_{\mathrm{s}}$ is the standard deviation of $\ln r$.

The soil structural index utilized the concept of the Kullback-Leibler Distance (KLD) (Kullback, 1951) between two probability density functions $f_{s}(x)$ and $f_{R}(x)$ and is defined as:

$$
K L D=\int f_{s}(x) \ln \left\{f_{s}(x) / f_{R}(x)\right\} d x
$$

If $f_{s}(x)$ represents the probability density function of the structured soil and $f_{R}(x)$ the probability density function of the reference pore size distribution calculated from soil particle size distribution following Chan and Govindaraju (2004). If both distributions are lognormal with parameters $\left(\mu_{R}, \sigma_{R}^{2}\right)$ and $\left(\mu_{s}, \sigma_{s}^{2}\right)$, KLD can be expressed as (El-Baz and Nayak, 2004):

$$
K L D=\ln \sigma_{R}-\ln \sigma_{s}-\frac{1}{2}+\frac{\sigma_{s}^{2}+\left(\mu_{s}-\mu_{R}\right)^{2}}{2 \sigma_{R}^{2}}
$$

where the parameter values are obtained by fitting with the Kosugi (1996) lognormal water retention model the soil water retention curves of the structured soil and the water retention curve derived from the reference pore size distribution. Details on this equation can be found in Yoon (2009).

Pedo-Transfer Functions (PTFs) for the Estimation of Water Retention Curves The van Genuchten (1980) water retention model parameters were estimated with the software ROSETTA (Schaap et al., 2001) from information on soil texture (sand, silt, and clay fractions), bulk density, and measured water content at -33 and at $-1500 \mathrm{kPa}$. When only parameters $n$ and $a$ of the van Genuchten (1980) model of water retention were reported, the geometric mean of pressure potential, $\psi_{s}$, and standard deviation, $\sigma_{s}$, of the Kosugi (1996) lognormal water retention model were obtained by:

$$
\psi_{s}=\psi_{0} \exp \left(\sigma_{s}^{2}\right)
$$

where $\psi_{0}$ is the mode of a distribution defined as:

$$
\psi_{0}=\frac{m^{1-m}}{\alpha}
$$

and:

Table 2. Symbols and actual sizes of structure types as function of their qualitative (field) description (after Nikiforoff, 1941).

\begin{tabular}{cccc}
\hline \hline \multirow{2}{*}{ Structure type } & \multicolumn{3}{c}{ Size } \\
\cline { 2 - 4 } & Fine & Medium & Coarse \\
\hline Platy & $\mathrm{S} 1(1-2 \mathrm{~mm})$ & $\mathrm{S} 2(2-5 \mathrm{~mm})$ & $\mathrm{S} 3(5-10 \mathrm{~mm})$ \\
Prismatic & $\mathrm{S} 4(10-20 \mathrm{~mm})$ & $\mathrm{S} 4(10-50 \mathrm{~mm})$ & $\mathrm{S} 6(50-100 \mathrm{~mm})$ \\
Blocky & $\mathrm{S} 3(5-10 \mathrm{~mm})$ & $\mathrm{S} 2(2-5 \mathrm{~mm})$ & $\mathrm{S} 3(5-50 \mathrm{~mm})$ \\
Granular & $\mathrm{S} 1(1-2 \mathrm{~mm})$ & $\mathrm{mm})$ \\
\hline
\end{tabular}




$$
\sigma_{s}^{2}=(1-m) \ln \left[\frac{2^{1 / m}-1}{m}\right]
$$

where $m=1-1 / n$.

\section{Pedo-Transfer Functions (PTFs) for the Estimation of}

$\mathbf{K}_{\text {sat }}$ A total of 1359 data points from the original 1468 data points were used to estimate saturated hydraulic conductivity $\left(\mathrm{K}_{\mathrm{sat}}, \mathrm{cm}\right.$ day $\left.{ }^{-1}\right)$ using seven different PTFs (Table 3), including a prediction with the computer program ROSETTA (Schaap et al., 2001) with the same options selected for the estimation of the van Genuchten (1980) water retention model parameters. The van Genuchten (1980) model parameters required by the $\mathrm{K}_{\text {sat }}$ model of Han et al. (2008) were estimated with the Wosten et al. (1999) and ROSETTA (Schaap et al., 2001) models. The two procedures are identified in Fig. 1 as Han, 2008 (Wosten) and Han, 2008 (ROSETTA), respectively and are considered as two independent predictions. The PTFs of Han et al. (2008), ROSETTA and Wösten et al. (1999) showed less variance in their estimation than others (Fig 1). Rawls et al. (1998) estimated the lowest $\mathrm{K}_{\text {sat }}$ with a large variance.
There may be intrinsic correlations between KLD and $\mathrm{K}_{\text {sat }}$ values because the PTFs used to estimate water retention curves for KLD estimations use the same physical properties to estimate $\mathrm{K}_{\text {sat. }}$ In this study, $\mathrm{K}_{\text {sat }}$ estimations using seven different methods were averaged to simulate the natural variability of $\mathrm{K}_{\mathrm{sat}}$ and to diminish the correlation problem between KLD and $\mathrm{K}_{\text {sat. }}$ Guber et al. (2006) called this approach multi model ensemble prediction and showed that it is an effective tool to predict hydrological variables.

\section{A Categorical Principal Component Analysis (CATPCA)} A Categorical Principal Component Analysis (CATPCA) as implemented in the statistical software package SPSS (SPSS Inc., Chicago, IL, USA) was utilized to transform field soil morphological descriptions into quantitative variables. ACATPCA explores relationships among descriptors having various measurement types (e.g., numerical, ordinal, or nominal) as an optimization problem using an alternating least squares algorithm (Ellis et al., 2006). The optimal scaling is a transformed quantity from the descriptors by the algorithm searching for the optimal mean squared correlation between optimal scaling and the components. It does so by changing the component loadings and their quantifications. Combining categorical variables with optimal

Table 3. Selected PTFs for the estimation of $K_{\text {sat }}\left(\mathrm{cm} \mathrm{day}^{-1}\right)$ and water retention parameters of the van Genuchten (1980) model.

\begin{tabular}{|c|c|}
\hline Model & Equation \\
\hline \multicolumn{2}{|r|}{ For $K_{\text {sat }}$ estimation } \\
\hline Wösten et al. 1999 & $\begin{array}{l}\mathrm{K}_{\text {sat }}=1.15741 \exp \left[7.755+0.0352 \text { silt }+0.93 \text { topsoil }-0.967 \mathrm{D}^{2}-0.000484 \text { clay }^{2}-0.000322 \mathrm{silt}^{2}+0.01 / \text { silt }\right. \\
-0.0748 / \mathrm{om}-0.643 \ln (\text { silt })-0.01398 \mathrm{D} \text { clay }-0.1673 \mathrm{D} \text { om }+0.02986 \text { topsoil clay }-0.03305 \text { topsoil silt }]\end{array}$ \\
\hline Brakensiek et al. 1984 & $\begin{array}{l}\mathrm{K}_{\text {sat }}=27.8 \text { exp }\left(19.52348 \theta_{\mathrm{s}}-8.96847-0.028212 \text { clay }+1.8107 \cdot 10^{-4} \mathrm{sand}^{2}-9.4125 \cdot 10^{-3} \text { clay }^{2}-8.395215 \theta_{\mathrm{s}}^{2}\right. \\
+0.077718 \text { sand } \theta_{\mathrm{s}}-0.00298 \text { sand }^{2} \theta_{\mathrm{s}}^{2}-0.019492 \text { clay }^{2} \theta_{\mathrm{s}}^{2}+1.73 \cdot 10^{-5} \text { sand }^{2} \text { clay }+0.02733 \text { clay }^{2} \theta_{\mathrm{s}}+ \\
\left.0.001434 \text { sand }^{2} \theta_{\mathrm{s}}-3.5 \cdot 10^{-6} \text { clay }^{2} \text { sand }\right)\end{array}$ \\
\hline Saxton et al. 1986 & $\mathrm{~K}_{\text {sat }}=27.78 \exp \left[12.012-7.55 \cdot 10^{-2}\right.$ sand $+\left(-3.895+3.671 \cdot 10^{-2}\right.$ sand -0.1103 clay $+8.7546 \cdot 10^{-4}$ clay $\left.\left.^{2}\right) / \theta_{s}\right]$ \\
\hline Rawls et al. 1998 & $5361 \theta_{e f f}^{m}$ \\
\hline Han et al. 2008 & $K_{s a t}=20 \phi_{\mathrm{inf}}^{\frac{-S}{\theta_{s}}+3}$ \\
\hline Schaap et al. 2001 & No equation available, neural network approach using software ROSETTA to estimate $\mathrm{K}_{\text {sat. }}$. \\
\hline
\end{tabular}

For the van Genuchten water retention model parameters ( $\alpha$ and $n)$

$\mathrm{a}=\exp \left[-14.96+0.03135\right.$ clay +0.0351 silt +0.646 om $+15.29 \mathrm{D}-0.192$ topsoil $-4.671 \mathrm{D}^{2}-0.000781$ clay $2-0.00687 \mathrm{om}_{2}+0.0449 / \mathrm{om}+0.0663 \ln (\mathrm{silt})+0.1482 \ln (\mathrm{om})-0.04546 \mathrm{D}$ silt $-0.4852 \mathrm{D}$ om +0.00673

Wösten et al. 1999 topsoil clay]

$\mathrm{n}=\exp \left[-25.23-0.02195\right.$ clay +0.0074 silt -0.194 om $+45.5 \mathrm{D}-7.24 \mathrm{D}_{2}+0.0003658$ clay $^{2}+0.002885$ $\mathrm{om}^{2}-12.81 / \mathrm{D}-0.1524 / \mathrm{silt}-0.01958 / \mathrm{om}-0.2876 \ln (\mathrm{silt})-0.0709 \ln (\mathrm{om})-44.6 \ln (\mathrm{D})-0.02264 \mathrm{D}$ clay $+0.0896 \mathrm{D}$ om +0.00718 topsoil clay]

Schaap et al. $2001 \quad$ No equation available, neural network approach using software ROSETTA to estimate a and n. $\theta_{\mathrm{s}}=$ saturated water content; $\theta_{\mathrm{inf}}=$ soil water content at the inflection point of the matric potential; $\phi_{\text {inf }}=\theta_{\mathrm{s}}-\theta_{\text {inf }} \theta_{e f f}^{m}=$ saturated water content - water content at field capacity $\mathrm{b}=$ the Campbell parameter $\mathrm{m}=3-(1 / \mathrm{b}) \mathrm{D}=\operatorname{dry}$ bulk density $\left(\mathrm{g} / \mathrm{cm}^{3}\right)$; om $=\%$ organic matter content; topsoil $=$ a dumy variable $(1$ for topsoil, 0 for subsoil); clay $=\%$ clay content; silt $=\%$ silt content; sand $=\%$ sand content; $\mathrm{S}=\mathrm{n}\left(\theta_{\mathrm{s}}-\theta_{\mathrm{r}}\right)[(2 \mathrm{n}-1) /(\mathrm{n}-1)]^{(1 / \mathrm{n}-1)}$. 


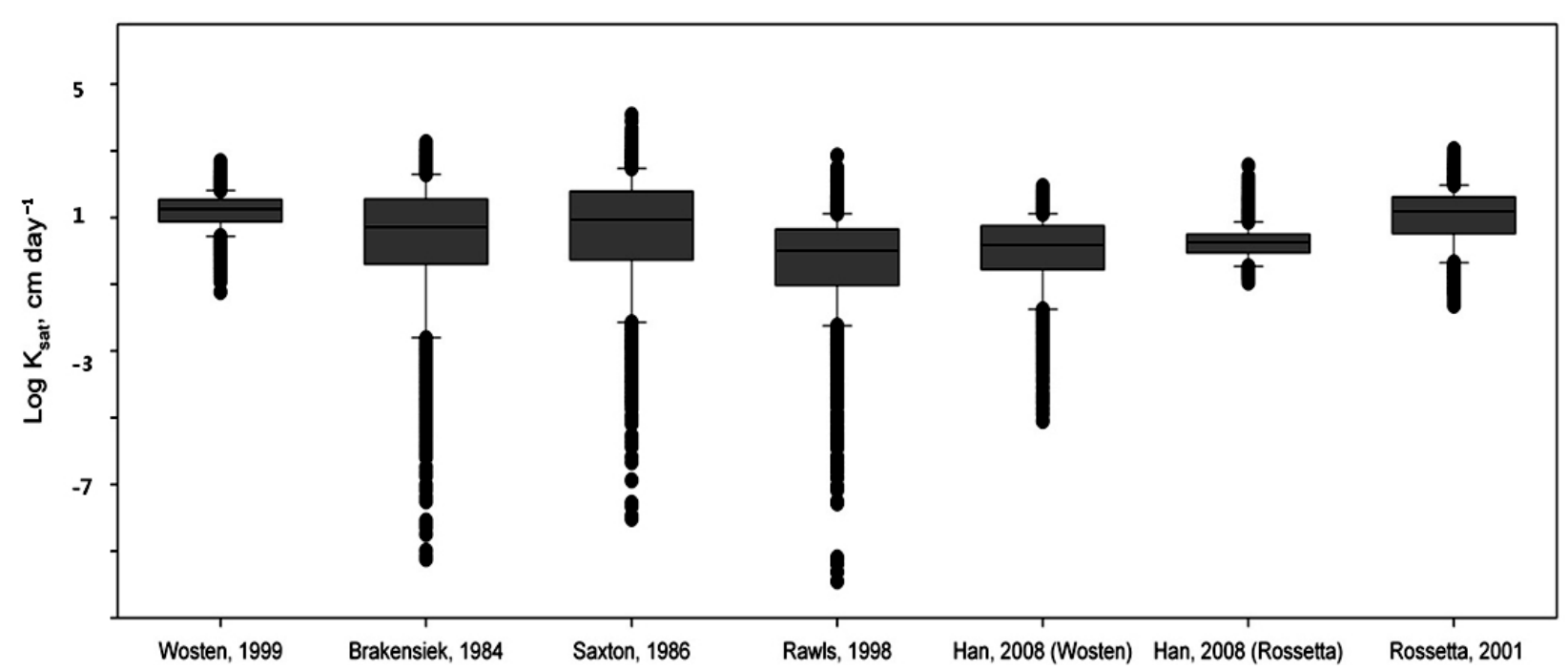

Fig. 1. Box-plot of the estimated saturated hydraulic conductivities from multiple PTFs. A bar is the 5 and 95 percentiles and the black circles are outliers.

scaling into the principal components maximizes the variance explained by the principal components for the data set (Calero et al., 2008; Ellis et al., 2006; Gifi, 1990; Meulman and Heiser, 1999). As an additional useful outcome, the optimal scaling can describe non linear relationships among those categorical variables and can also be useful for other analyses such as cluster analyses (Calero et al., 2008). In this study, texture and shape classes were assigned as multiple nominal types whereas the rest of the field morphological descriptions including size (Table 2) were assigned as ordinal type. Details on the criteria used for the selection of measurement type can be found in Carlero et al. (2008).

The Two Step Clustering Technique The quantitatively transformed categorical variables from CATPCA were used in the two-step clustering procedure to identify homogeneous groups within a dataset. Among the advantages of the technique are an automatic selection of the number of clusters, the ability to handle both categorical and continuous variables, and the ability to handle large data sets. The procedures are summarized as follows: 1) pre-clustering the cases into many small clusters, and 2) re-cluster the small clusters into the appropriate number of clusters. The appropriate numbers of clusters were found with the Schwarz's Bayesian Criterion (BIC) or the Akaike Information Criterion (AIC) for each number of clusters within a specified range. Then, hierarchical clustering is performed on the initial estimate and the final clusters are defined by finding the largest increase in Log-Likelihood distance between the closest clusters in each stage (SPSS Inc., 2007).
Statistical Approaches The stepwise linear regression technique was conducted to estimate $\mathrm{K}_{\text {sat }}$ using KLD and the quantitatively transformed field morphological descriptions using CATPCA. ANOVA and non-parametric approaches such as the Kruskal-Wallice H and Mann-Whitney U tests were used to test significance of differences in measured soil properties, of parameters of estimated water retention curves $\left(\theta_{\mathrm{s}}, \theta_{\mathrm{r}}, \Psi_{\mathrm{m}}, \sigma\right)$, of averaged $\mathrm{K}_{\text {sat, }}$, and of KLD related to texture classes, structure types, and size classes. The Kruskal-Wallis $\mathrm{H}$ test is a useful nonparametric alternative to one-way analysis of variance for multiple samples in case that the variance and sample sizes are not equal. If the $\mathrm{H}$ test confirms differences among groups, then pairwise comparisons using the Mann-Whitney test or Post-Hoc analysis with Tamahnes's T2 were used to identify details among variables. Data resulting from the CATPCA and the two-step clustering were subject to a classification and regression tree with a Chi-square Automatic Interaction Detector (CHAID) (Kass, 1980) to infer potential relationships among KLD and soil physical properties (clay content, W33, and bulk density), and newly classified clusters using the two-step cluster analysis.

According to visual evaluations of histograms of all variables, OM and KLD were log-transformed for statistical tests requiring normal distributions (e.g., ANOVA).

\section{Results and Discussion}

General Characterization of the Dataset Values of log $\mathrm{OM}$, of water contents at $-33 \mathrm{kPa}$ (W33), and at $-1500 \mathrm{kPa}$ 
(W1500), and bulk density (BD) were significantly different $(p<0.001)$ across texture classes (Table 4$)$. In agreement with results by Olness and Archer (2005) and Petersen et al., (1996), average texture class OM followed a linear relationship with clay. However, the linear relationship was not as strong when individual points were considered (Pearson correlation coefficient of $0.114, p<0.001$ ). There were positive correlations between $\mathrm{W} 33$ and clay content (Pearson correlation coefficient of $0.514, p<0.001$ ), between $\log \mathrm{OM}$ and W1500 (Pearson correlation coefficient of 0.787, $p<0.001$ ), and between OM and BD (Pearson correlation coefficient of $-492, p<0.001)$. Petersen et al. (1996) reported strong correlation among clay and OM, CEC, and W1500. The literature reported contradictory results on the effects of OM on water retention values such as W33 and W1500 (Rawls et al., 2003). Recently, Olness and Archer (2005) analyzed more than 100,000 points and showed that both W33 and W1500 were correlated to clay contents, which is in agreement with results in this study.

Clay content, $\log \mathrm{OM}, \mathrm{W} 33, \mathrm{~W} 1500$, and BD were significantly different $(p<0.05)$ among structure type classes (Table 4). Differences in clay content were mainly due to soils with a prismatic soil structure type $(p<0.01)$. Bulk density (BD) and log OM were significantly different among all shape classes $(p<0.05)$. Prismatic soils have the highest clay content, W33, W1500, and BD but the lowest OM. Rawls and Pachepsky (2002) used a regression tree approach to estimate W33 and found that the blocky and prismatic structure types had smaller averaged water content at $-33 \mathrm{kPa}$. Their results are different than those in this study, but results in Rawls and Pachepsky (2002) comprised a subset of the data (weak grade and soft/dry

Table 4. Summary of soil physical properties in the US National Pedon Characterization database.

\begin{tabular}{|c|c|c|c|c|c|c|c|c|c|c|c|}
\hline & \multirow{2}{*}{$\mathrm{N}$} & \multicolumn{5}{|c|}{ Mean } & \multicolumn{5}{|c|}{ Std. Deviation } \\
\hline & & Clay, \% & OM, \% & W33, \% & $\mathrm{W} 1500, \%$ & $\mathrm{BD}, \mathrm{Mg} / \mathrm{m}^{-3}$ & Clay & $\mathrm{OM}$ & W33 & W1500 & $\mathrm{BD}$ \\
\hline \multicolumn{12}{|l|}{ Textural class* } \\
\hline S & 67 & 4.89 & 0.49 & 12.06 & 3.89 & 1.59 & 2.65 & 0.54 & 5.76 & 2.06 & 0.13 \\
\hline LS & 64 & 6.93 & 1.31 & 16.45 & 6.60 & 1.56 & 2.96 & 1.93 & 8.40 & 2.53 & 0.19 \\
\hline SL & 315 & 12.45 & 1.44 & 22.39 & 9.92 & 1.53 & 4.40 & 2.65 & 8.21 & 4.04 & 0.23 \\
\hline $\mathrm{L}$ & 224 & 19.15 & 1.85 & 28.73 & 14.05 & 1.47 & 4.79 & 2.51 & 6.55 & 4.75 & 0.20 \\
\hline $\mathrm{SiL}$ & 498 & 16.69 & 1.91 & 33.12 & 13.69 & 1.40 & 6.59 & 2.37 & 6.25 & 4.45 & 0.18 \\
\hline $\mathrm{Si}$ & 6 & 6.75 & 0.54 & 34.32 & 9.13 & 1.46 & 3.85 & 0.56 & 5.19 & 5.24 & 0.13 \\
\hline SCL & 63 & 23.75 & 1.15 & 26.81 & 15.90 & 1.57 & 2.73 & 1.24 & 5.52 & 4.34 & 0.20 \\
\hline CL & 29 & 28.37 & 1.94 & 32.99 & 18.47 & 1.51 & 1.12 & 3.06 & 6.23 & 3.87 & 0.20 \\
\hline $\mathrm{SiCL}$ & 154 & 31.89 & 2.77 & 36.80 & 20.21 & 1.47 & 3.38 & 4.03 & 5.84 & 3.75 & 0.21 \\
\hline $\mathrm{SiC}$ & 37 & 48.45 & 2.22 & 40.75 & 26.31 & 1.59 & 5.10 & 2.71 & 4.25 & 5.20 & 0.20 \\
\hline $\mathrm{C}$ & 11 & 61.61 & 3.69 & 42.51 & 28.90 & 1.57 & 2.59 & 4.43 & 7.55 & 4.61 & 0.45 \\
\hline \multicolumn{12}{|l|}{ Soil structure type } \\
\hline Crumble \& Granular & 189 & 17.34 & 4.05 & 27.38 & 12.31 & 1.37 & 9.54 & 4.26 & 8.83 & 5.44 & 0.23 \\
\hline Platy & 143 & 17.19 & 2.01 & 29.45 & 13.03 & 1.44 & 10.23 & 2.38 & 8.57 & 5.37 & 0.18 \\
\hline Blocky & 955 & 18.38 & 1.49 & 28.71 & 13.46 & 1.50 & 10.50 & 2.24 & 10.13 & 6.50 & 0.21 \\
\hline Prismatic & 181 & 20.73 & 0.81 & 30.53 & 15.03 & 1.53 & 10.38 & 0.81 & 7.89 & 5.39 & 0.19 \\
\hline \multicolumn{12}{|l|}{ Size class } \\
\hline s1 & 196 & 16.94 & 3.64 & 28.22 & 12.58 & 1.38 & 9.81 & 4.31 & 8.62 & 5.45 & 0.22 \\
\hline s2 & 122 & 18.22 & 2.54 & 28.76 & 13.00 & 1.43 & 9.99 & 2.36 & 9.19 & 5.48 & 0.19 \\
\hline s3 & 300 & 17.67 & 1.64 & 28.43 & 13.30 & 1.49 & 10.80 & 2.29 & 10.31 & 6.82 & 0.21 \\
\hline s4 & 744 & 18.68 & 1.36 & 28.96 & 13.57 & 1.50 & 10.31 & 2.16 & 9.75 & 6.21 & 0.21 \\
\hline s5 & 79 & 21.65 & 0.82 & 31.17 & 15.76 & 1.51 & 8.49 & 0.72 & 7.83 & 4.90 & 0.17 \\
\hline s6 & 27 & 21.53 & 0.89 & 28.23 & 14.24 & 1.61 & 15.03 & 0.78 & 10.12 & 7.32 & 0.19 \\
\hline Total & 1468 & 18.42 & 1.78 & 28.84 & 13.46 & 1.48 & 10.38 & 2.66 & 9.60 & 6.17 & 0.21 \\
\hline
\end{tabular}

*: $\mathrm{S}=$ sand; $\mathrm{LS}=$ loamy sand $\mathrm{SL}=$ sandy loam; $\mathrm{L}=$ loam; $\mathrm{SiL}=$ silt loam; $\mathrm{Si}=$ silt; $\mathrm{SCL}=$ sandy clay loam; $\mathrm{CL}=$ clay loam $\mathrm{SiCL}$ $=$ silty clay loam; $\mathrm{SiC}=$ silty clay; $\mathrm{C}=$ clay. 
consistency class).

Soils with structural units of estimated sizes between 2 and $5 \mathrm{~cm}$ (S5, Table 2) had the highest values of W33 and W1500 (Table 4). Except W33 ( $p=0.283)$, other variables were significantly different $(p<0.005)$ among size classes. Except W33 and OM, values of clay content, W1500, and bulk density increased with aggregate size. Kay and Dexter (1990) also found that clay content increased as aggregate size increased. On the other hand, results in this study are different than in previous ones that reported a positive correlation between aggregate sizes and water retention (Tamboli et al. 1964), and a negative correlation between aggregate size and bulk density (Wittmuss and Mazurak, 1958). However, the cited studies considered aggregates smaller than $2 \mathrm{~cm}$, whereas in this study aggregates were as large as $10 \mathrm{~cm}$. Organic matter content $(\mathrm{OM})$ decreased significantly as aggregate size increased $(p<0.001)$. Tamboli et al. (1964) pointed out that OM is mainly placed on the external surface of aggregates and, therefore, it is negatively correlated to aggregate size. It is worth noting that no clear trend or significant difference in W33 was found among size classes. These results differ from the finding of Pachepsky et al. (2006), who reported 2-5\% smaller values of W33 in large soil aggregates. However, they used a qualitative scale of aggregate sizes (small, medium and large), each of which would contain a mix of actual sizes (see Table 2)

Estimated $\mathrm{K}_{\mathrm{sat}}$ and parameters of the Kosugi (1994) model were significantly different across texture classes. Clay content had positive correlation with $\theta_{\mathrm{r}}$ (Pearson correlation coefficient of $0.551, p<0.001)$ and negative correlation with $\mathrm{K}_{\text {sat }}$ (Pearson correlation coefficient of $-0.718, p<$ 0.001). These results were expected because PTFs used in their estimation utilized soil texture as main inputs. The relationship between water retention and soil texture are

Table 5. Water retention properties of soils in the US National Pedon Characterization database estimated with ROSETTA (Schaap et al., 2001).

\begin{tabular}{|c|c|c|c|c|c|c|c|c|c|c|c|}
\hline & \multirow{2}{*}{$\mathrm{N}$} & \multicolumn{5}{|c|}{ Mean } & \multicolumn{5}{|c|}{ Std. Deviation } \\
\hline & & $\theta_{\mathrm{s}}, \mathrm{g} / \mathrm{g}$ & $\theta_{\mathrm{r}}, \mathrm{g} / \mathrm{g}$ & $\Psi_{\mathrm{m}}, \mathrm{kPa}$ & $\sigma$ & $\mathrm{K}_{\text {sat }}, \mathrm{cm} \mathrm{day}^{-1}$ & $\theta_{\mathrm{s}}$ & $\theta_{\mathrm{r}}$ & $\Psi_{\mathrm{m}}$ & $\sigma$ & $\mathrm{K}_{\mathrm{sat}}$ \\
\hline \multicolumn{12}{|l|}{ Texture class } \\
\hline S & 67 & 0.36 & 0.03 & 2.52 & 1.33 & 2.21 & 0.03 & 0.01 & 53.40 & 0.29 & 0.22 \\
\hline LS & 64 & 0.37 & 0.04 & 4.59 & 1.40 & 1.96 & 0.05 & 0.02 & 108.37 & 0.34 & 0.30 \\
\hline SL & 315 & 0.38 & 0.04 & 6.42 & 1.57 & 1.53 & 0.06 & 0.01 & 132.24 & 0.26 & 0.45 \\
\hline $\mathrm{L}$ & 224 & 0.40 & 0.05 & 9.07 & 1.60 & 1.06 & 0.05 & 0.02 & 150.73 & 0.30 & 0.46 \\
\hline $\mathrm{SiL}$ & 498 & 0.42 & 0.06 & 20.68 & 1.36 & 1.18 & 0.04 & 0.02 & 250.34 & 0.33 & 0.56 \\
\hline $\mathrm{Si}$ & 6 & 0.42 & 0.06 & 48.83 & 1.05 & 1.48 & 0.04 & 0.02 & 451.36 & 0.47 & 0.48 \\
\hline $\mathrm{ScL}$ & 63 & 0.39 & 0.06 & 2.52 & 1.81 & 1.13 & 0.05 & 0.02 & 24.61 & 0.21 & 0.47 \\
\hline CL & 29 & 0.42 & 0.07 & 8.08 & 1.70 & 0.73 & 0.05 & 0.01 & 87.59 & 0.28 & 0.40 \\
\hline $\mathrm{SiCL}$ & 154 & 0.45 & 0.08 & 15.71 & 1.66 & 0.59 & 0.05 & 0.02 & 251.58 & 0.45 & 0.45 \\
\hline $\mathrm{SiC}$ & 37 & 0.45 & 0.08 & 8.54 & 2.06 & 0.44 & 0.05 & 0.02 & 115.24 & 0.48 & 0.43 \\
\hline $\mathrm{C}$ & 11 & 0.46 & 0.08 & 6.55 & 2.27 & 1.22 & 0.10 & 0.03 & 112.96 & 0.65 & 0.92 \\
\hline \multicolumn{12}{|l|}{ Soil structure type } \\
\hline Crumble \& Granular & 189 & 0.43 & 0.05 & 9.55 & 1.50 & 1.44 & 0.06 & 0.03 & 164.06 & 0.31 & 0.64 \\
\hline Platy & 143 & 0.41 & 0.06 & 15.50 & 1.46 & 1.25 & 0.05 & 0.02 & 245.44 & 0.36 & 0.61 \\
\hline Blocky & 955 & 0.40 & 0.05 & 12.74 & 1.52 & 1.26 & 0.06 & 0.02 & 208.81 & 0.38 & 0.61 \\
\hline Prismatic & 181 & 0.40 & 0.06 & 11.74 & 1.59 & 1.04 & 0.05 & 0.02 & 186.08 & 0.38 & 0.54 \\
\hline \multicolumn{12}{|l|}{ Size class } \\
\hline s1 & 196 & 0.42 & 0.05 & 10.72 & 1.51 & 1.43 & 0.06 & 0.03 & 197.58 & 0.32 & 0.61 \\
\hline s2 & 122 & 0.42 & 0.06 & 14.50 & 1.45 & 1.23 & 0.05 & 0.04 & 217.04 & 0.35 & 0.65 \\
\hline s3 & 300 & 0.40 & 0.05 & 12.11 & 1.52 & 1.31 & 0.06 & 0.02 & 206.40 & 0.38 & 0.62 \\
\hline s4 & 744 & 0.40 & 0.05 & 13.02 & 1.53 & 1.23 & 0.05 & 0.02 & 209.10 & 0.39 & 0.60 \\
\hline s5 & 79 & 0.41 & 0.06 & 10.88 & 1.59 & 1.01 & 0.04 & 0.02 & 181.48 & 0.33 & 0.55 \\
\hline s6 & 27 & 0.38 & 0.05 & 9.67 & 1.61 & 1.07 & 0.04 & 0.02 & 134.75 & 0.43 & 0.49 \\
\hline Total & 1468 & 0.41 & 0.05 & 12.47 & 1.52 & 1.26 & 0.06 & 0.02 & 205.17 & 0.37 & 0.61 \\
\hline
\end{tabular}


well known and constitute the bases for PTFs development (Pachepsky et al., 2006).

Among shape classes, significant differences were found in saturated hydraulic conductivity, $\mathrm{K}_{\text {sat }}(p<0.001)$, saturated water content, $\theta_{\mathrm{s}}(p<0.001)$, and the standard deviation of the mean soil pore size, $\sigma(p=0.014)$, but no significant differences in residual water content, $\theta_{\mathrm{r}}(p=0.739)$, and geometric mean of soil pore size, $\Psi_{\mathrm{m}}(p=0.061)$ were found (Table 5). Values of $\mathrm{K}_{\text {sat }}$ were significantly lower in soils with prismatic soil structure type $(p<0.003)$ and higher in soils with granular soil structure type $(p<0.005)$. These results may be driven by the negative correlation between $\mathrm{BD}$ and $\mathrm{K}_{\mathrm{sat}}$ (Pearson coefficient of $\left.-0.475, p<0.001\right)$. Lin et al. (1999) also reported that soil structure type granular had greater values of $\mathrm{K}_{\text {sat }}$ than any other soil structure type due to a greater amount of inter-aggregate porosity in the granular soil structure type. On the other hand, Bouma and Anderson (1997) compared $\mathrm{K}_{\text {sat }}$ values from prismatic and blocky structures and found greater values of $\mathrm{K}_{\text {sat }}$ in the former that in the latter soil structure type. The discrepancy could be caused by the influence of texture within each soil structure type (Lin et al., 1999). Soils with fine texture and with structure type prismatic often present greater $\mathrm{K}_{\text {sat }}$ because of the development of macropores between aggregates (prisms), but soils with medium texture and prismatic structure type often have smaller $\mathrm{K}_{\text {sat }}$ than soils of blocky type.

The saturated water content, $\theta_{\mathrm{s}}(p<0.001)$, and $\mathrm{K}_{\text {sat }}(p<$

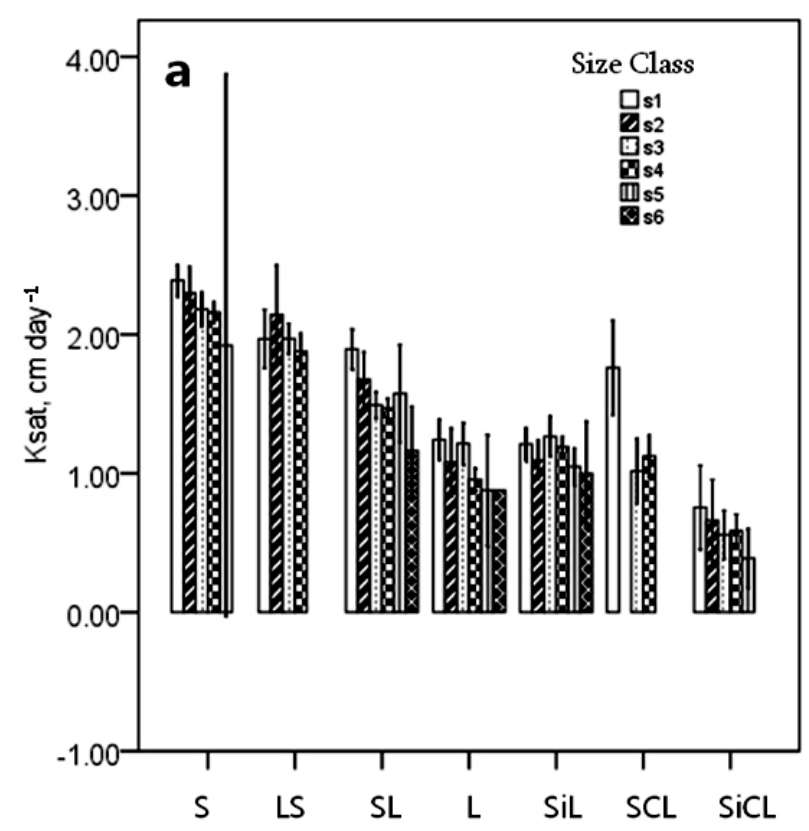

0.001) were statistically different among aggregate size groups. Within each texture class, $\mathrm{K}_{\text {sat }}$ and $\theta_{\mathrm{s}}$ decreased as aggregate size increased (Fig. 2). It is related to the increase of clay content with aggregate size (Table 4). Greater $\mathrm{K}_{\text {sat }}$ in smaller aggregates may also correspond to results of Kosugi (1997) who found that smaller structural units had smaller $\Psi_{\mathrm{m}}$. Horn (1994) pointed out that $\mathrm{K}_{\mathrm{sat}}$ through single aggregates were lower than $\mathrm{K}_{\text {sat }}$ between aggregates (intraaggregate flow), which would imply smaller $\mathrm{K}_{\text {sat }}$ values in larger aggregates due to a predominance of inter-aggregate flow over intra-aggregate flow.

Values of KLD were highly correlated to clay content (Pearson correlation coefficient of $0.526, p<0.001$ ). Clay was an important grouping parameter in the estimation of W33 in regression trees (Pachepsky et al., 2006). There were significant differences $(p<0.001)$ in KLD among texture classes. Sandy soils had the lowest KLD values, which reflect the relationship between KLD and clay content. According to an ANOVA test, there were no statistical differences in $\operatorname{KLD}(p=0.051)$ among size classes but size S5 had significantly greater KLD values than other size classes.

Field Morphological Descriptions using CATPCA The two-dimensional solution with eigenvalues greater than 1 accounted for $49.2 \%$ of the variance from CATPCA using variables derived from morphological field descriptions (Table 6). This variance is lower than those in Calero et al.

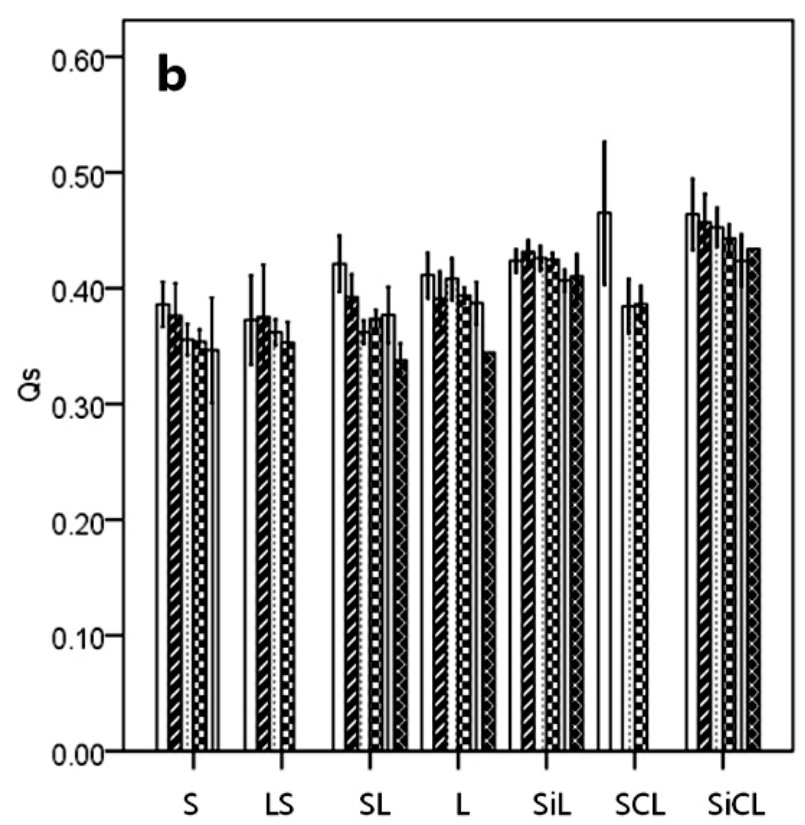

Fig. 2. Estimated values of a) saturated hydraulic conductivity $\left(K_{\text {sat }}\right)$ and $\left.b\right)$ saturated water content $\left(\theta_{s}\right)$ plotted as functions of soil textural and size classes. See text for details in the estimation procedures. 

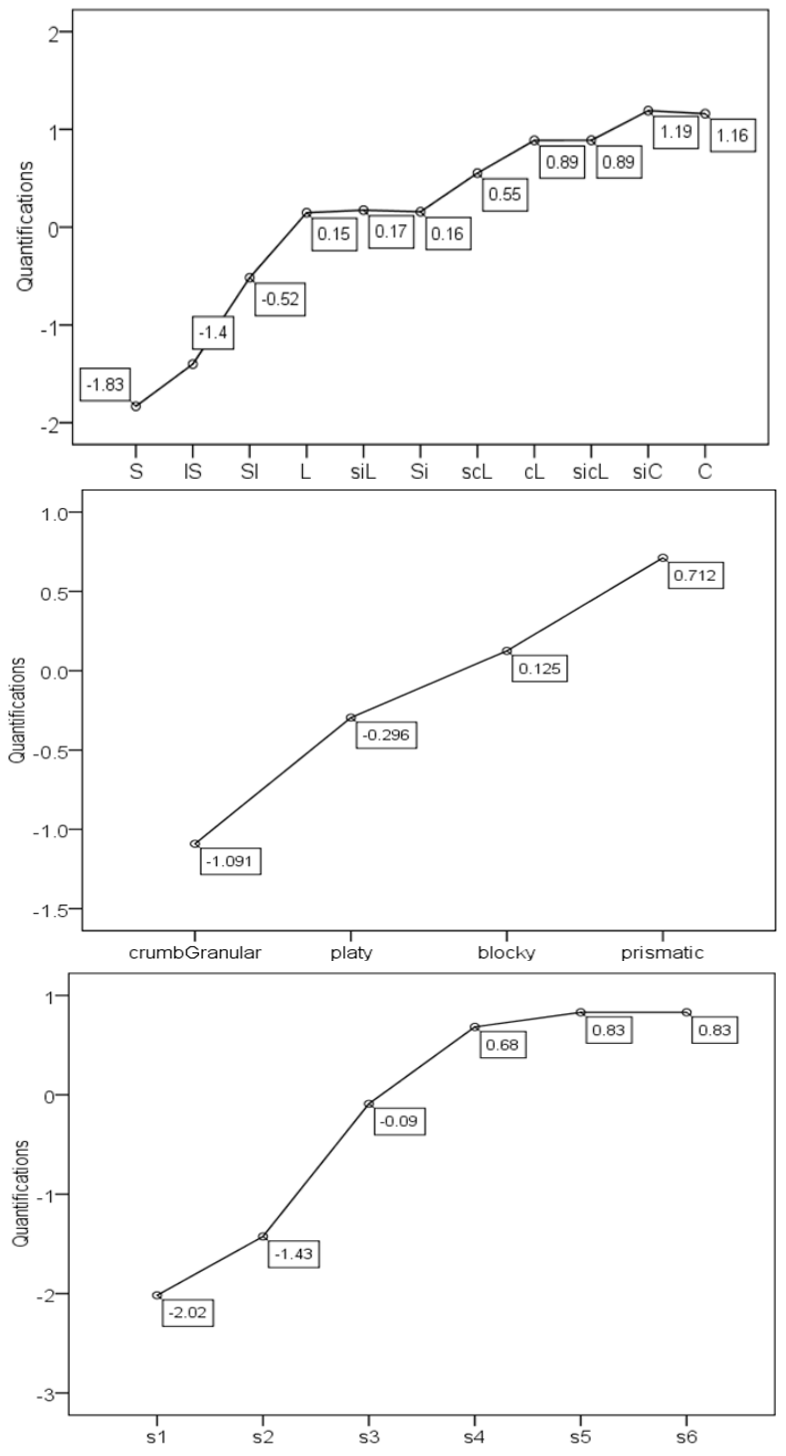

Fig. 3. Optimal scaling values for (a) texture classes, (b) shape classes, and (c) size classes obtained from a Categorical Principal Component Analysis (CATPCA).
(2008) and Scalenghe et al. (2000) who utilized similar procedures. Their model accounted for around $80 \%$ of the variance but used 17 variables as opposed to only 8 variables (texture, shape, grade, moisture, dryness, stickiness, plasticity, and size class) used in this study. Indeed the purpose of CATPCA in this study was to quantify field morphological variables. A different approach was used by Lilly et al. (2008), who assigned dummy values to different levels of qualitative variables.

Non linear characteristics of morphological properties were found in the transformation (Fig. 3). Mean values of optimal scaling were assigned to each category of the variables. The optimal scaling of multiple nominal variables such as texture and shape class were their centroid coordinate values. Soils in very coarse texture classes had negative scores (Fig. 3a). The approximate linear characteristics of shape classes (Fig. 3b) are in agreement with results in Calero et al. (2008). Increases of optimal scales from granular soil structure type to others such as blocky and prismatic were related to the clay content that was shown to be correlated to those classes (Calero et al., 2008). For aggregate sizes, soils can be grouped in two groups based on the sign of the optimal scaling values (Fig 3c). The first group showing negative optimal scaling values contains smaller size classes (s1, s2, s3) than the second group, which shows positive optimal scaling values (s4, s5, s6). Shape classes in the joint plot were closely located to size classes indicating high correlation because shape class information was already implicitly included in the size class category (Fig. 4a). The coordinates of the end point of vectors for stickiness and plasticity given by object scores were close together indicating high

Table 6. Variance Accounted For (VAF) of texture class and morphological variables considered in CATPCA.

\begin{tabular}{|c|c|c|c|c|c|c|c|c|c|}
\hline & \multicolumn{3}{|c|}{ Centroid Coordinates } & \multicolumn{3}{|c|}{ Vector Coordinates } & \multicolumn{3}{|c|}{ Total } \\
\hline & \multicolumn{2}{|c|}{ Dimension } & \multirow{2}{*}{ Mean } & \multicolumn{2}{|c|}{ Dimension } & \multirow{2}{*}{ Total } & \multicolumn{2}{|c|}{ Dimension } & \multirow{2}{*}{ Total } \\
\hline & 1 & 2 & & 1 & 2 & & 1 & 2 & \\
\hline Texture $^{\dagger}$ & 0.467 & 0.128 & 0.298 & & & & 0.467 & 0.128 & 0.298 \\
\hline Shape class ${ }^{\dagger}$ & 0.235 & 0.786 & 0.51 & & & & 0.235 & 0.786 & 0.51 \\
\hline Grade class & 0.218 & 0.097 & 0.158 & 0.217 & 0.093 & 0.31 & 0.217 & 0.093 & 0.31 \\
\hline Moisture class & 0.065 & 0.007 & 0.036 & 0.065 & 0.007 & 0.072 & 0.065 & 0.007 & 0.072 \\
\hline Dry class & 0.319 & 0.011 & 0.165 & 0.319 & 0.011 & 0.33 & 0.319 & 0.011 & 0.33 \\
\hline Sticky class & 0.655 & 0.062 & 0.359 & 0.655 & 0.061 & 0.716 & 0.655 & 0.061 & 0.716 \\
\hline Plasticity class & 0.713 & 0.053 & 0.383 & 0.713 & 0.052 & 0.765 & 0.713 & 0.052 & 0.765 \\
\hline Size class & 0.203 & 0.781 & 0.492 & 0.192 & 0.746 & 0.937 & 0.192 & 0.746 & 0.937 \\
\hline Total eigenvalue & 2.874 & 1.925 & 2.4 & 2.159 & 0.97 & 3.129 & 2.861 & 1.884 & 3.937 \\
\hline Variance Accounted For ${ }^{\ddagger}$ & 35.93 & 24.06 & 29.995 & 35.987 & 16.165 & 52.151 & 35.757 & 23.55 & 49.210 \\
\hline
\end{tabular}

${ }_{\dagger}^{\dagger}$ indicates multiple nominal variable. ${ }^{\ddagger} \mathrm{VAF}$ indicates variance explained by variable considered in principal component. 
correlation between them. The cosines of the vector angles for variables indicated no correlation between shape class and other variables, and strong correlations among plasticity, stickiness, and moisture classes. On the first dimension, all variables have positive component loadings and, with the exception of size class, all variables are negative in the second dimension (Fig. 4b). As structural unit size decreases, the grade of soil structural elements tends to become stronger. Therefore, the second dimension will define a contrast between these two variables. Quantification of field morphological descriptions obtained from optimal scaling would be useful for other statistical analysis requiring variables in numerical type.

Using transformed values from categorical morphological variables, stepwise linear regression analysis was performed to estimate $\mathrm{K}_{\text {sat. }}$. In addition to the transformed morphological variables, KLD was included as a predictor. The selected final model resulted in $\mathrm{K}_{\text {sat }}(\mathrm{cm} /$ day $)=1.291-0.345^{*}$ Texture - 0.109*Stickiness - 0.094*Dryness - $0.057 * \log (\mathrm{KLD})$ $0.059 *$ Plasticity $-0.029 *$ Size $-0.031 *$ Grade with an $r^{2}=$ 0.484 and $p=0.018$ (Fig. 5). Interestingly, size class and KLD were selected in the final model, whereas structure type and moisture classes were excluded. All selected variables in the final model were statistically significant and no collinearity problem was detected. KLD and size class were considered important in the final stepwise regression model.

Clay was an important variable, followed by aggregate size and shape class when KLD was estimated by regression tree analysis (Fig. 7). It should be noted that size class $(\mathrm{F}=$ $12.51)$ is more informative than shape class $(F=6.63)$.
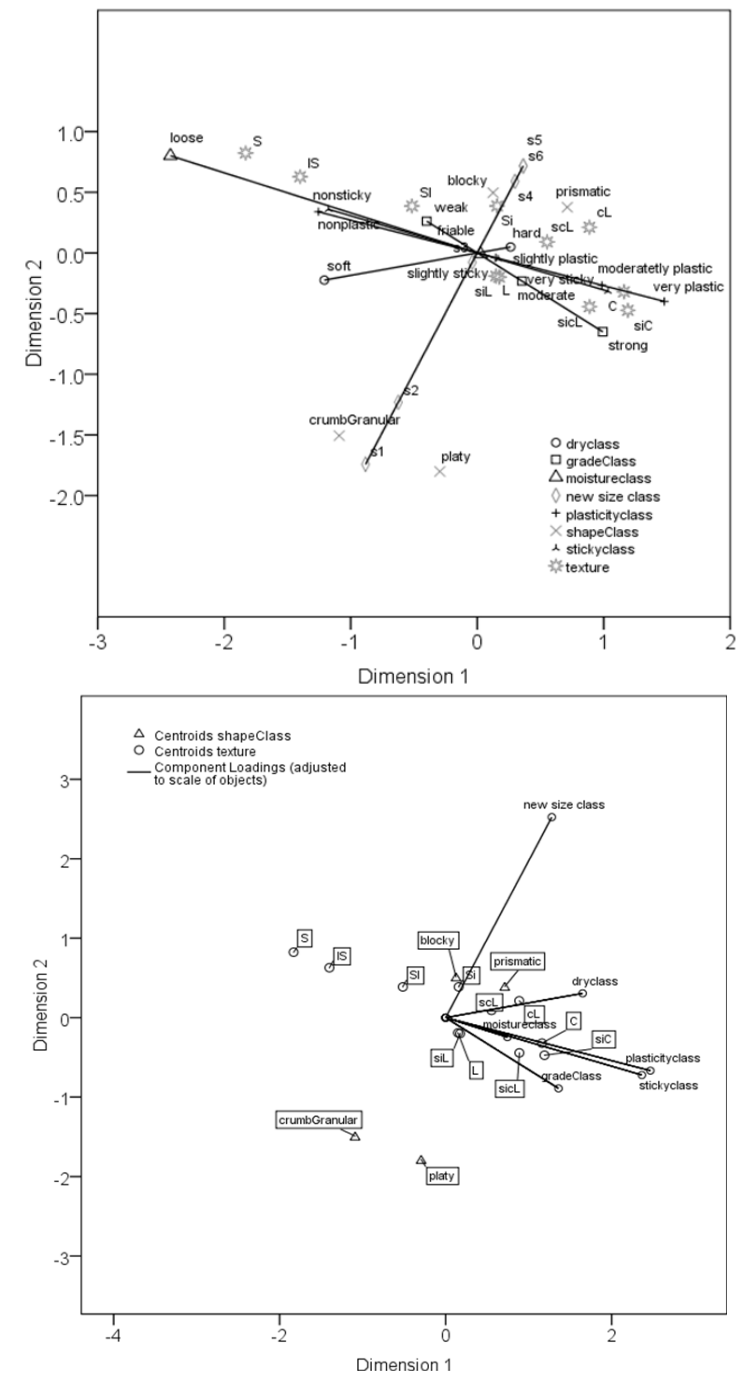

Fig. 4. (a) Quantifications in joint plot of the category points of each of the morphological variables, and (b) plot of component loadings for ordinal variables with vector and multiple nominals for centroid coordinates.

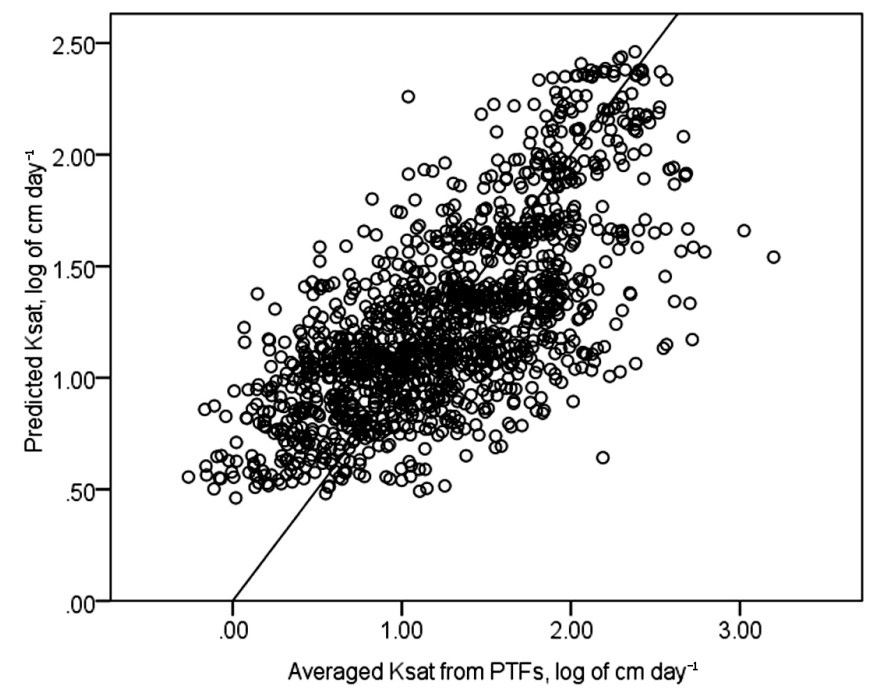

Fig. 5. Averaged $K_{\text {sat }}$ from estimation with seven models (see Table 3) vs. $K_{\text {sat }}$ estimated with stepwise linear regression from morphological variables and KLD (the line indicates a 1:1 relationship). 

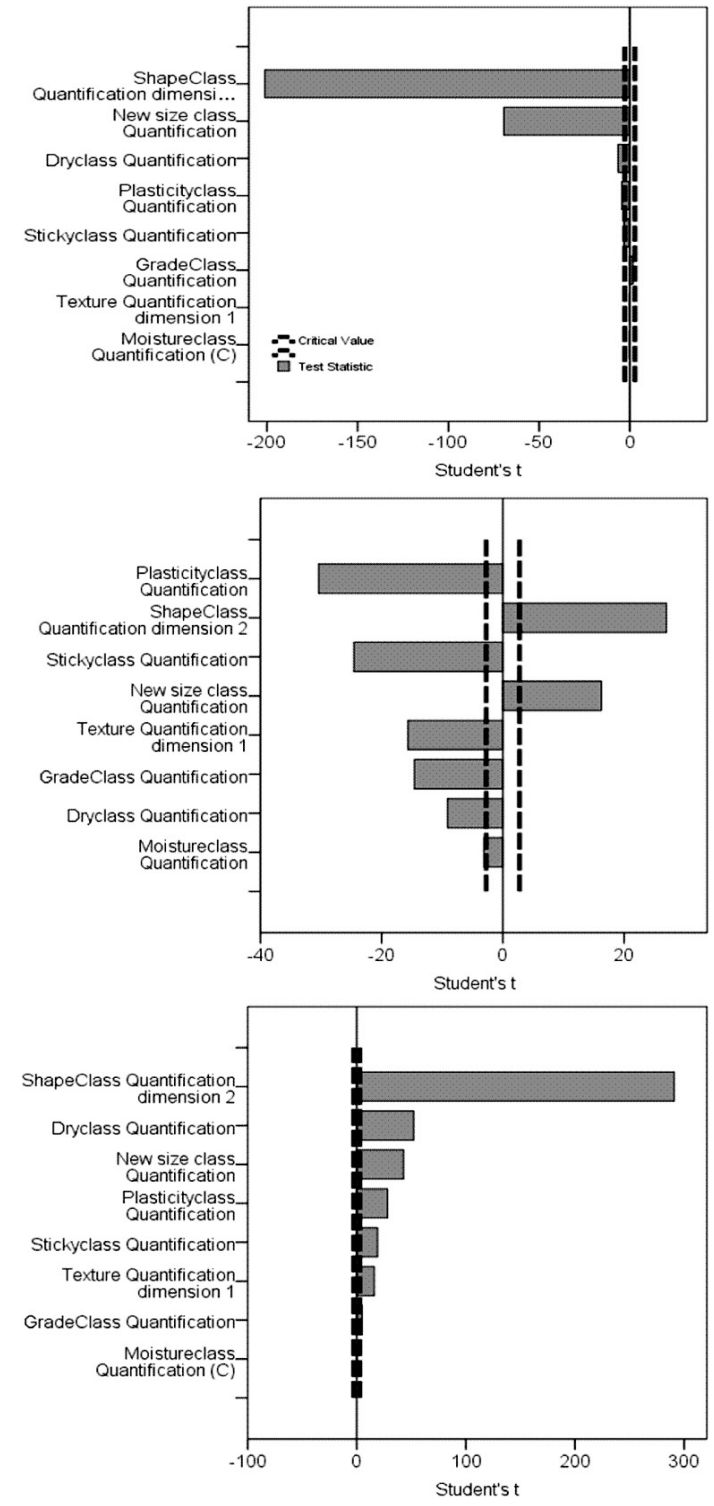

Fig. 6. Significance chart for variables in (a) cluster 1, (b) cluster 2, and (c) cluster 3 .
Transformed field morphological variables presented significant correlations to many physical properties (Table 7). Values of KLD were correlated to texture. Although Pachepsky and Rawls (2003) considered grade class as the most important variable for the estimation of $\mathrm{W} 33$ or water content at -10 $\mathrm{kPa}$, in this study stickiness and plasticity class were more related to W33. Stickiness and plasticity were also highly correlated to clay content and to $\mathrm{K}_{\text {sat. }}$ Although nonlinear transformation of field morphological descriptions helped to identify quantitative relationship to other measured soil properties, quantified field morphological variables were not strongly correlated to physical properties that are related to soil structure, such as bulk density, W33, $\Psi_{\mathrm{m}}$, and KLD.

\section{Characteristics of Custered Groups using Field Mophological}

Descriptions The reduction of data into a smaller number of homogeneous groups is helpful for the identification of the effect of soil structure. Three groups were identified by the two-step clustering analysis and approximately half of the data was assigned to cluster 3 (Table 8). The number of groups was determined based on the maximized ratio of distance measures using Bayesian Information Criteria. Within each group, transformed field morphological variables

Table 8. Number of samples assigned to each of 3 clusters by the two-step clustering technique.

\begin{tabular}{ccc}
\hline \hline Cluster & $\mathrm{N}$ & \% of Total \\
\hline 1 & 325 & 22.1 \\
2 & 336 & 22.9 \\
3 & 807 & 55.0 \\
\hline Total & 1468 & $100 \%$ \\
\hline
\end{tabular}

Table 7. Correlation coefficients among transformed morphological descriptors and physical and hydraulic variables in the US National Pedon Characterization database.

\begin{tabular}{lcccccccc}
\hline \hline & Texture & Structure type & Grade & Moisture & Dryness & Stickiness & Plasticity & Size \\
\hline BD & $-.132^{* *}$ & $.190^{* *}$ & $.071^{* *}$ & -0.01 & $.190^{* *}$ & $.104^{* *}$ & $.089^{* *}$ & $.212^{* *}$ \\
Clay & $.739^{* *}$ & $.056^{*}$ & $.253^{* *}$ & $.135^{* *}$ & $.279^{* *}$ & $.547^{* *}$ & $.549^{* *}$ & $.069^{* *}$ \\
Log OM & $.294^{* *}$ & $-.313^{* *}$ & $.076^{* *}$ & $.097^{* *}$ & $-.127^{* *}$ & $.052^{*}$ & $.060^{*}$ & $-.350^{* *}$ \\
W33 & $.666^{* *}$ & 0.025 & $.287^{* *}$ & $.135^{* *}$ & $.262^{* *}$ & $.432^{* *}$ & $.492^{* *}$ & 0.033 \\
W1500 & $.695^{* *}$ & $.068^{* *}$ & $.299^{* *}$ & $.152^{* *}$ & $.307^{* *}$ & $.528^{* *}$ & $.535^{* *}$ & $.073^{* *}$ \\
$\mathrm{~K}_{\text {sat }}$ & $-.607^{* *}$ & $-.081^{* *}$ & $-.279^{* *}$ & $-.155^{* *}$ & $-.379^{* *}$ & $-.537^{* *}$ & $-.536^{* *}$ & $-.115^{* *}$ \\
Qs & $.410^{* *}$ & $-.123^{* *}$ & $.081^{* *}$ & 0.049 & -0.011 & $.167^{* *}$ & $.174^{* *}$ & $-.139^{* *}$ \\
Qr & $.531^{* *}$ & -0.007 & $.197^{* *}$ & $.100^{* *}$ & $.210^{* *}$ & $.344^{* *}$ & $.328^{* *}$ & 0.001 \\
$\mathrm{~h}_{\mathrm{m}}$ & $.159^{* *}$ & 0.005 & $.086^{* *}$ & 0.002 & $.068^{* *}$ & 0.032 & $.087 * *$ & 0.015 \\
sigma & $.217^{* *}$ & $.052^{*}$ & $.113^{* *}$ & $.066^{*}$ & $.114^{* *}$ & $.251^{* *}$ & $.232^{* *}$ & 0.047 \\
Log KLD & $.439^{* *}$ & -0.021 & $.137^{* *}$ & $.081^{* *}$ & $.154^{* *}$ & $.379^{* *}$ & $.352^{* *}$ & -0.015 \\
\hline
\end{tabular}

\footnotetext{
**, Statistically significant at $\mathrm{a}=0.05$.
} 
Table 9. Means and standard deviations of quantitatively transformed values of qualitative variable for each cluster.

\begin{tabular}{lcccccc}
\hline \hline & \multicolumn{2}{c}{ Cluster 1 } & \multicolumn{2}{c}{ Cluster 2 } & \multicolumn{2}{c}{ Cluster 3 } \\
\cline { 2 - 7 } & Mean & Std. deviation & Mean & Std. deviation & Mean & Std. deviation \\
\hline Texture & -0.004 & 0.648 & -0.630 & 0.739 & 0.264 & 0.468 \\
Shape & -1.634 & 0.146 & 0.441 & 0.300 & 0.474 & 0.046 \\
Grade & 0.105 & 1.086 & -0.533 & 0.669 & 0.180 & 1.003 \\
Moisture & 0.105 & 0.000 & -0.354 & 2.054 & 0.105 & 0.000 \\
Dryness & -0.439 & 1.244 & -0.643 & 1.291 & 0.445 & 0.242 \\
Stickiness & -0.170 & 0.976 & -1.009 & 0.752 & 0.489 & 0.727 \\
Plasticity & -0.236 & 0.980 & -1.149 & 0.693 & 0.573 & 0.578 \\
Size & -1.717 & 0.446 & 0.423 & 0.477 & 0.516 & 0.342 \\
\hline
\end{tabular}

were lined up vertically in descending order of importance (Fig. 6). For a variable to be significant, the absolute value of the $t$-statistic should exceed the boundaries defined by the vertical dashed lines representing the critical value. In cluster 1 , shape class was most significant with negative $t$-statistics, followed by size classes. In cluster 3 size and shape classes were most significant, but with positive $t$-statistics. Dryness and size class with positive and significant $t$-statistics followed. The separation of variables into clusters can be confirmed by their centroids (Table 9). Mean value of cluster 1 for quantified texture class is between mean values of cluster 2 and cluster 3 , indicating texture between coarse (cluster 3) and fine (cluster 2). Cluster 1 contained mostly small size of granular and platy structural types. It should be noted that cluster 2 consisted of lower values for all variables except shape and size classes.

The selection of the clusters were based only on field morphological descriptions and can, therefore, be considered independent of the physical properties of soils and of the KLD values associated to the morphological properties. Regression tree analysis was performed to identify the significance of physical properties in the estimation of these clusters (Fig. 7). Bulk density, clay, W33, and KLD, considered important variables for soil structure characterization, were used as dependant variables for the estimation of the three clusters. The best predictor for the estimation of the three clusters was W33 (Fig. 7a). Node 1 for water content less than $15.40 \%$ and it was composed mainly by samples in cluster 2. The main predictor of Node 2 (W33 between 15.40 and $20.50 \%$ ) was KLD. Node 2 contained about $10 \%$ of the total data equally distributed among the three clusters. KLD values less than 0.91 was assigned to cluster 2 samples, whereas cluster 3 that contained the largest number of data points. Samples from cluster 3 containing the largest number of data points defined the group with
W33 greater than $24.40 \%$ that was related to clay content.

Grade class is considered an important grouping parameter in the estimation of W33 or W10 (Pachepsky and Rawls, 2003). In this study, texture and KLD were the most important predictors and were superior to grade class in the estimation of W33 (Fig. 7b). Without KLD and texture, grade class was the most important variable, which validates the result by Pachepsky and Rawls (2003). Size classification was also an important grouping parameter in the tree. The differences between results in Pachepsky and Rawls (2003) and the results in this study may have been caused by the optimal scaling introduced by CATPCA. When considering categorical variables directly in a regression tree, results were similar to Pachepsky and Rawls (2003) except for plasticity class appearing superior to grade class. Indeed, plasticity was better correlated with water retention properties that grade in this data set (Table 7). While the relationship between conventional descriptors of soil structure such as shape classes and KLD was unclear, differences in KLD among clusters were significant $(\mathrm{p}<0.001)$, which suggests that KLD is an important variable for the description of soil structure.

\section{Conclusions}

Soil structure is described as mostly categorical variables, thus limiting their use in PTFs or other modeling scenarios. In this study, categorical morphological descriptions were transformed to quantitative values using CATPCA. In a regression tree analysis, KLD turned out to be an important factor for explaining clusters selected by a two-step clustering procedure using morphological variables. Although this study provides an advanced method relating soil structure description to KLD, the same approach should be tested using a datasets containing measured hydraulic properties. 
(a)

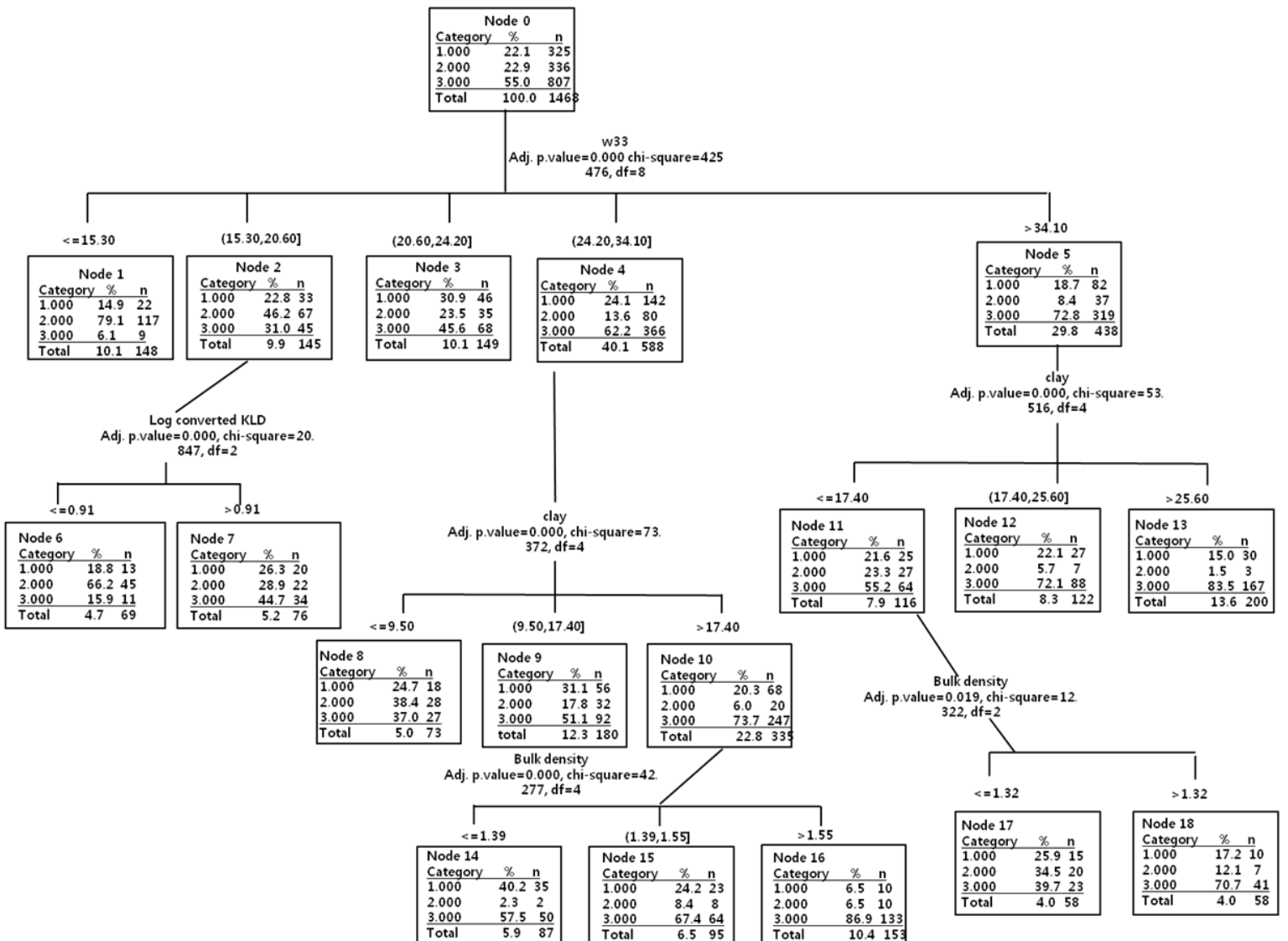

(b)

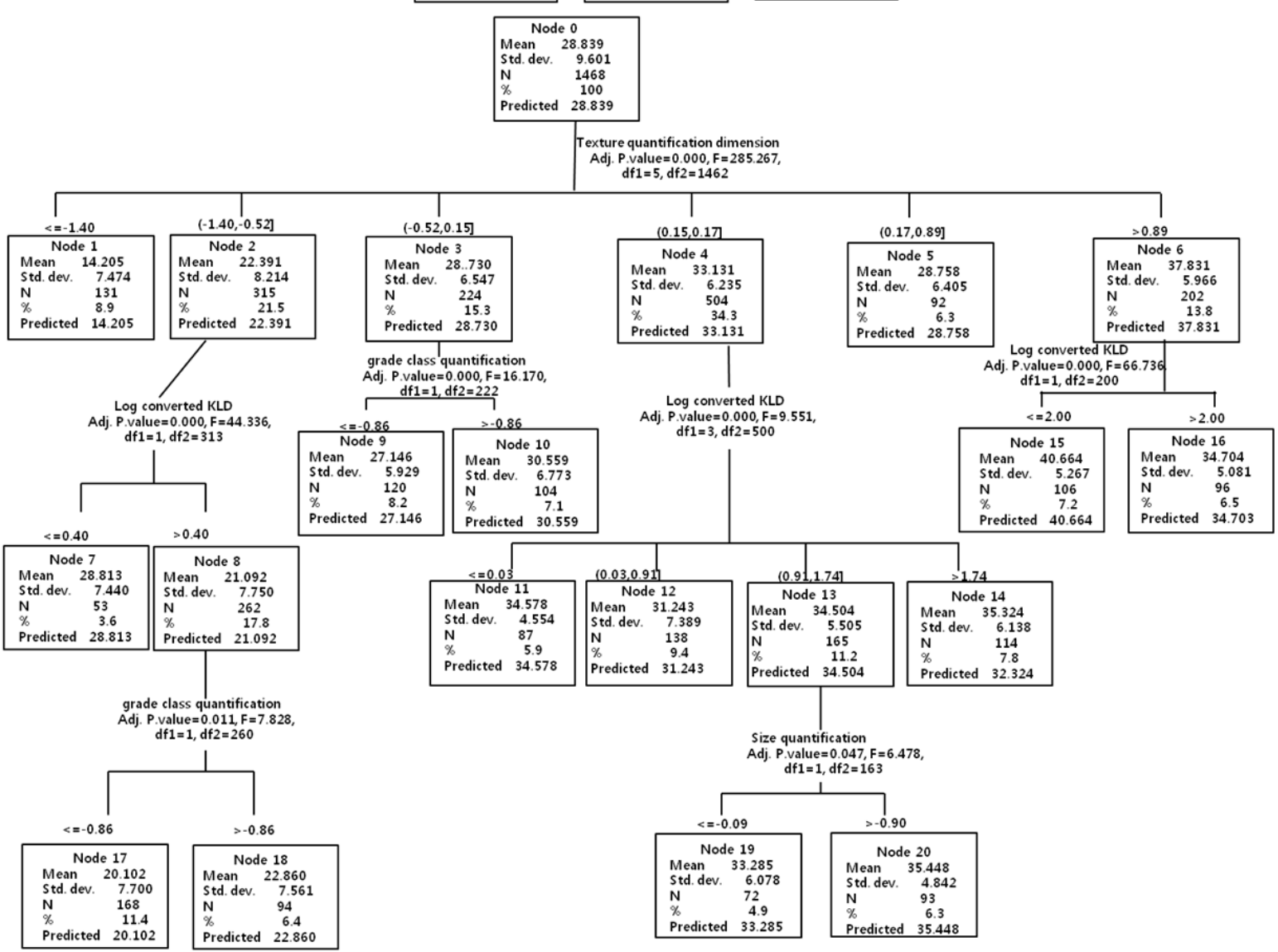

Fig. 7. Regression tree to estimate; (a) three clusters from the two-step clustering and (b) W33 from texture classes, field morphological variables, and KLD. Partitioning range of variables is shown above the box and the $F$ statistics to test for significance of the variables is shown beneath each variable name. 
More insight on the predictive power of KLD to estimate hydraulic properties would be achieved by considering measured $\mathrm{K}_{\text {sat }}$ and water retention.

\section{Acknowledgements}

This study was partially supported by 2011 Post-doctoral Fellowship Program (NO. 200902OFT102865016) of National Academy of Agricultural Science, Rural Development Administration, Republic of Korea and USDA NRCS, USA.

\section{References}

Bouma, J., and J.L. Anderson. 1997. Water movement through pedal soils. I. Saturated flow. Soil Sci. Soc. Am. J. 41:413-418.

Brakensiek, D.L., W.J. Rawls, and G.R. Stephenson. 1984. Modifying SCS hydrologic soil groups and curve numbers for rangeland soils. ASAE Paper No. PNR-84-203, St. Joseph,MI.

Calero, J., R. Delgado, G. Delgado, and J.M. Martin-Garcia. 2008. Transformation of categorical field soil morphological properties into numerical properties for the study of chronosequences. Geoderma 145:278-287.

Chan, T.P., and R.S. Govindaraju. 2004. Estimating soil water retention curve from particle-size distribution data based on polydisperse sphere systems. Vadose Zone J. 3 (4):1443-1454.

El-Baz and Nayak, 2004. Efficiency of composite sampling for estimating a lognormal distribution. Environ.Ecol.Stat.11:283-294

Ellis, R.N., P.M. Kroonenberg, B.D. Harch, and K.E. Basford. 2006. Non-linear principal components analysis: an alternative method for finding patterns in environmental data. Environmetrics 17:1-11.

Gifi, A. 1990. Nonlinear Multivariate Analysis. John Wiley, Chichester, UK.

Guber, A.K., W.J. Rawls, E.V. Shein, and Y.A. Pachepsky. 2003. Effect of soil aggregate size distribution on water retention. Soil Sci. 168:223-233.

Guber A.K., Y.A. Pachepsky, M.T.van Genuchten, W.J. Rawl, J. Simunek, D. Jacques, T.J. Nicholson, and R.E. Cady. 2006. Fieldscale water flow simulations using ensembles of pedotransfer functions for soil water retention. Vadose Zone J. 5 (1):234-247.

Han, H., D. Gimenez, and A. Lilly. 2008. Textural averages of saturated soil hydraulic conductivity predicted from water retention data. Geoderma. 146:121-128

Holden, N.M. 1995. Temporal variation in ped shape in an old pasture soil. Catena 24:1-11.

Horn, R., H. Taubner, M. Wuttke, and T. Baumgarlt. 1994. Soil physical-properties related to soil-structure. Soil till. Res. 30:187-216.

Kass, G.V. 1980. An exploratory technique for investigating large quantities of categorical data. J. Appl. Statist. 229:119-127.

Kay, B.D., and A.R. Dexter. 1990. Influence of aggregate diameter, surface-area and antecedent water-content on the dispersibility of clay Can. J. Soil Sci. 70:655-671.

Kosugi, 1996. Lognormal distribution model for unsaturated soil hydraulic properties. Water Resour. Res. 32:2697-2703.
Kosugi, K. 1997. A new model to analyze water retention characteristics of forest soils based on soil pore radius distribution. J. Forest Res. 2:1-8.

Kullback, L. 1951. On information and sufficiency. Ann. Math. Stat. 22:79-86.

Levine, E.R., D.S. Kimes, and V.G. Sigillito. 1996. Classifying soil structure using neural networks. Ecol. Model. 92:101-108.

Lilly, A., A. Nemes, W.J. Rawls, and Y.A. Pachepsky. 2008. Probabilistic approach to the identification of input variables to estimate hydraulic conductivity. Soil Sci. Soc. Am. J. 72:16-24.

Lin, H.S., K.J. McInnes, L.P. Wilding, and C.T. Hallmark. 1999. Effects of soil morphology on hydraulic properties: I. Quantification of soil morphology. Soil Sci. Soc. Am. J. 63:948-954.

McKenzie, D.C., T.S. Abbott, and F.R. Higginson. 1991. The effect of irrigated crop production on the properties of a sodic vertisol. Aust. J. Soil Res. 29:443-453.

Meulman, J.J., and W.J. Heiser. 1999. SPSS Categories 10.0. SPSS Inc, Chicago, IL.

Nemes, A., W.J. Rawls, and Y.A. Pachepsky. 2006. Use of the nonparametric nearest neighbor approach to estimate soil hydraulic properties. Soil Sci. Soc. Am. J. 70:327-336.

Nikiforoff, C.C. 1941. Morphological classificaton of soil structure. Soil Sci. 52:193-212.

Olness, A. and D. Archer. 2005. Effect of organic carbon on available water in soil. Soil Sci. 170:90-101.

Pachepsky, Y.A., and W.J. Rawls. 2003. Soil structure and pedotransfer functions. Eur. J. Soil Sci. 54:443-451.

Pachepsky, Y.A., W.J. Rawls, and H.S. Lin. 2006. Hydropedology and pedotransfer functions. Geoderma 131:308-316.

Petersen, L.W., P. Moldrup, O.H. Jacobsen, and D.E. Rolston. 1996. Relations between specific surface area and soil physical and chemical properties. Soil Sci. 161:9-21.

Rawls, W.J., and Y.A. Pachepsky. 2002. Soil consistence and structure as predictors of water retention. Soil Sci. Soc. Am. J. 66:1115-1126.

Rawls, W.J., D. Gimenez, and M. Grossman. 1998. Use of soil texture, bulk density, and slope of wter retention curve to predict saturated hydrualic conductivity. Trans. ASAE 41:983-988.

Rawls, W.J., Y.A. Pachepsky, J.C. Ritchie, T.M. Sobecki, and H. Bloodworth. 2003. Effect of soil organic carbon on soil water retention. Geoderma 116:61-76.

Saxton, K.E., W.J. Rawls, J.S. Romberger, and R.I. Papendick. 1986. Estimating generalized soil-water characteristics from texture. Soil Sci. Soc. Am. J. 50 (4):1031-1036.Schaap, M.G., F.J. Leij, and M.T. van Genuchten. 2001. ROSETTA: a computer program for estimating soil hydraulic parameters with hierarchical pedotransfer functions. J. Hydrol. 251:163-176.

Schaetzl, R.J., and S. Anderson. 2005. Soil Genesis and Geomorphology. Cambridge University Press, Cambridge, UK.

Scalenghe, R., E. Zanini, and D.R. Nielsen. 2000. Modeling soil development in a post-incisive chronosequence. Soil Sci. 165:455-462.

Tamboli, P.M., W.E. Larson, and M. Amemiya. 1964. Influence of aggregate size on soil moisture retention. Iowa Acad. Sci. 71:103-108.

Van Genuchten, 1980. A closed form equation for predicting the hydraulic conductivity of unsaturated soils. Soil Sci. Soc. Am. J. 44:892-989. 
Wittmuss, H.D., and A.P. Mazurak. 1958. Physical and chemical properties of aggregates in a Brunizem soil. Soil Sci. Soc. Am. Proc. 22:1-5.

Wösten, J.H.M., C. Schuren, J. Bouma, and A. Stein. 1990. Functional sensitivity analysis of 4 methods to generate soil hydraulic functions. Soil Sci. Soc. Am. J. 54:832-836.

Wösten, J.H.M., A. Lilly, A. Nemes, and C. Le Bas. 1999. Development and use of a database of hydraulic properties of European soils. Geoderma. 90:169-185.

Yoon S.W. 2009. A measure of soil structure derived from water retention properties: A kullback-Leibler distance approach. Ph.D. Dissertation. Rutgers, The State University of New Jersey, New Brunswick (UMI No. 3359187). 